\title{
Pre-eclampsia but not pregnancy-induced hypertension is a risk factor for diabetic nephropathy in type 1 diabetic women
}

\author{
D. Gordin • V. Hiilesmaa • J. Fagerudd • M. Rönnback • \\ C. Forsblom • R. Kaaja $\cdot$ K. Teramo $\cdot$ P.-H. Groop • \\ FinnDiane Study Group
}

Received: 28 September 2006 / Accepted: 30 October 2006 / Published online: 10 January 2007

(C) Springer-Verlag 2007

\begin{abstract}
Aims/hypothesis Our aim was to study whether preeclampsia and pregnancy-induced hypertension are predictors of diabetic nephropathy in type 1 diabetic women.

Materials and methods A total of 203 type 1 diabetic women, who were pregnant between 1988 and 1996 and followed at the Department of Obstetrics and Gynaecology in Helsinki, were re-assessed after an average of 11 years within the nationwide, multi-centre Finnish Diabetic Nephropathy Study. Diabetic nephropathy was defined as microalbuminuria, macroalbuminuria or end-stage renal disease.

Results Patients with prior pre-eclampsia had diabetic nephropathy more often than patients with a normotensive pregnancy (diabetic nephropathy vs normal albumin excretion rate: $41.9 \%$ vs $8.9 \%$; $p<0.001)$, whereas patients with a history of pregnancy-induced hypertension did not $(10.3 \%$
\end{abstract}

Electronic supplementary material Supplementary material is available in the online version of this article at http://dx.doi.org/ $10.1007 / \mathrm{s} 00125-006-0544-5$ and is accessible to authorised users.

D. Gordin · J. Fagerudd · M. Rönnback · C. Forsblom •

P.-H. Groop $(\square)$

Folkhälsan Research Center, Biomedicum Helsinki,

University of Helsinki,

Haartmaninkatu 8,

POB 63, FIN-00014 Helsinki, Finland

e-mail: per-henrik.groop@helsinki.fi

D. Gordin · J. Fagerudd · M. Rönnback $\cdot$ C. Forsblom •

P.-H. Groop

Department of Medicine, Division of Nephrology,

Helsinki University Central Hospital,

Helsinki, Finland

V. Hiilesmaa $\cdot$ R. Kaaja $\cdot$ K. Teramo

Department of Obstetrics and Gynaecology,

Helsinki University Central Hospital,

Helsinki, Finland vs $8.9 \% ; p=0.81)$. CHD was more prevalent in patients with a history of pre-eclampsia than in patients with a normotensive pregnancy $(12.2 \%$ vs. $2.2 \% ; p=0.03)$. Pre-eclampsia (odds ratio [OR] 7.7, 95\% CI 1.6-36.1; $p=0.01$ ) and $\mathrm{HbA}_{1 \mathrm{c}}$ (OR 2.0, 95\% CI 1.1-3.8; $p<0.05$ ) were associated with incident diabetic nephropathy even when adjusted for follow-up time, BMI, smoking, diabetes duration and age.

Conclusions/interpretation These data suggest that a history of pre-eclamptic pregnancy but not pregnancy-induced hypertension is associated with an elevated risk of diabetic nephropathy.

Keywords Coronary heart disease - Diabetic nephropathy . Pre-eclampsia $\cdot$ Pregnancy-induced hypertension .

Type 1 diabetes

\section{Abbreviations}

ESRD end-stage renal disease

FinnDiane Finnish Diabetic Nephropathy Study

\section{Introduction}

Pre-eclampsia is an important cause of maternal and fetal morbidity and mortality, and complicates $3-5 \%$ of all pregnancies [1-4]. It is characterised by hypertension, proteinuria and endothelial dysfunction during the second half of pregnancy. The incidence of pre-eclampsia in patients with type 1 diabetes is higher than in pregnant non-diabetic women, generally exceeding 10\% [5]. Pregnancy-induced hypertension is also twice as common in patients with type 1 diabetes than in non-diabetic women [6].

In patients with type 1 diabetes, pre-pregnancy microalbuminuria and proteinuria are the most important risk 
factors for pre-eclampsia [7-9]. The presence of retinopathy, poor glycaemic control, nulliparity and long duration of diabetes also increases this risk [10]. Although the clinical manifestations of pre-eclampsia disappear after delivery, the endothelial dysfunction seems to persist even years after a pre-eclamptic pregnancy $[3,11]$.

It is also known that in the general population a history of pre-eclampsia increases the risk of cardiovascular morbidity and mortality [12-14], but only a few studies have focused on the microvascular complications in type 1 diabetes. Pregnancy itself does not seem to be a major factor for diabetic microvascular complications [15]. Lovestam-Adrian et al. showed on the other hand that preeclampsia aggravates diabetic retinopathy, but it should be noted that patients in that study were followed for only 6 months after delivery [16]. A small retrospective study showed that proteinuria but not pre-eclampsia is a risk factor for nephropathy in women with type 1 diabetes [17]. Whether pre-eclampsia increases the risk of diabetic nephropathy is still unclear.

Diabetic nephropathy is characterised by an increasing urinary AER $[18,19]$, elevated blood pressure, a relentless decline in renal function, endothelial dysfunction and increased cardiovascular morbidity and mortality. Approximately one-third of patients with type 1 diabetes are at risk of diabetic nephropathy, which is one of the leading causes of end-stage renal disease (ESRD) in the West [20-22]. Poor glycaemic control, smoking, hypertension and still largely unknown predisposing genes are risk factors for nephropathy in type 1 diabetic patients [23, 24]. Interestingly, many of the factors associated with diabetic microvascular complications are also involved in the pathogenesis of pre-eclampsia suggesting that these entities may be closely linked [25].

The aim of this study was therefore to assess whether pre-eclampsia and pregnancy-induced hypertension predict the development of microvascular complications, with special emphasis on diabetic nephropathy, in women with type 1 diabetes.

\section{Subjects and methods}

Baseline (index pregnancy) The patients $(n=429)$ included at baseline were women with type 1 diabetes, who had been followed throughout their pregnancy and delivery at the Department of Obstetrics and Gynaecology, Helsinki University Central Hospital, between 1988 and 1996. This is the only centre responsible for the obstetric care of type 1 diabetic women in the greater Helsinki area with its population of 1.5 million inhabitants. The patients visited the hospital at 2-6-week intervals during pregnancy, starting at 6-10 pregnancy weeks. They were advised to measure their blood glucose at home five times daily on 2-3 days per week. They were prescribed long-acting insulin, one to three times daily, and short-acting insulin at meals in order to achieve good glycaemic control defined as a $\mathrm{HbA}_{1 \mathrm{c}}<7.5 \%$.

Blood pressure was measured at each visit after a 10-min rest in the sitting position. Measurements were made with a sphygmomanometer by midwives and nurses and blood pressure was considered elevated when diastolic blood pressure was repeatedly $\geq 90 \mathrm{mmHg}$ or if it increased by a minimum of $15 \mathrm{mmHg}$ during pregnancy. Urinary protein was measured by a dipstick method at every visit. If the dipstick repeatedly showed a + or a ++ result, suspected proteinuria was confirmed by a $24-\mathrm{h}$ urine collection. Proteinuria was defined as urinary protein excretion of $\geq 300 \mathrm{mg} / 24 \mathrm{~h}$.

Pre-eclampsia was defined as elevated blood pressure as described above, accompanied by proteinuria after 20 weeks of pregnancy. Pregnancy-induced hypertension was defined as elevated blood pressure in the absence of proteinuria [26, 27]. Patients with hypertension before 20 weeks of pregnancy were excluded from all analyses and the patients with proteinuria during the first half of pregnancy (White's class F) were excluded from the analyses for nephropathy. Importantly, 57 previous pregnancies from the period before 1988 were further assessed from the medical files in order to detect any possible pre-eclamptic pregnancies prior to the index pregnancy. Three new cases of pre-eclampsia were detected but two of them were classified as White's class F.

$\mathrm{HbA}_{1 \mathrm{c}}$ was measured monthly during pregnancy by HPLC (Diamat; Bio-Rad Laboratories, Hercules, CA, USA). The normal range was defined as a $\mathrm{HbA}_{1 \mathrm{c}}$ between 4.0 and $6.0 \%$. The first $\mathrm{HbA}_{1 \mathrm{c}}$ assessment during pregnancy was carried out between the 7th and 14th week of gestation. The mid-pregnancy value was obtained between the 20th and 25th week, and the third measurement approximately 2 weeks before delivery. The average $\mathrm{HbA}_{1 \mathrm{c}}$ value of each trimester was used in the analysis.

Follow-up study Out of the 429 baseline patients, 366 had one, 46 had two and 17 had more than two childbirths (total number of deliveries 590). Some patients could not be tracked and seven patients had died. Thus the total number of patients invited to the follow-up study was 396, of whom 196 accepted the invitation (Fig. 1). The seven patients who had died were also included in the analyses, using followup data retrieved from the hospital medical files. The follow-up visit took place on average 11 years after the index pregnancy, as part of the Finnish Diabetic Nephropathy (FinnDiane) Study, a nationwide, prospective, multicentre study initiated in November 1997. The aim of the FinnDiane study is to find the causes for diabetic late complications, especially nephropathy, in patients with type 


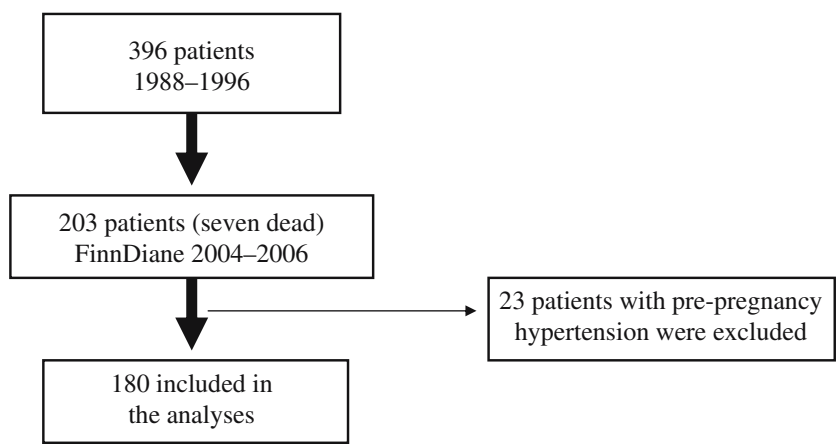

Fig. 1 Flow-chart of patients studied

1 diabetes. The study protocol is in accordance with the Declaration of Helsinki and was approved by the local ethics committees in each participating study centre. Written informed consent was obtained from each patient.

Data on medication, cardiovascular status and diabetic complications were registered by a standardised questionnaire, which was completed by the patient's attending physician and thus immediately verified from the medical files. CHD was defined as a positive history of myocardial infarction, bypass operation, a diagnostic finding in angiography or positive exercise test.

At the follow-up visit, fasting blood samples were drawn, for the determination of $\mathrm{HbA}_{1 \mathrm{c}}$, lipids, lipoproteins and serum creatinine. $\mathrm{HbA}_{1 \mathrm{c}}$ was analysed by immunoturbidimetry. Serum lipids were measured by automated enzymatic methods using an analyser (Cobas Mira; Hoffman-La Roche, Basel, Switzerland) and serum creatinine by routine enzymatic methods. Urinary AER was assessed from overnight and/or 24-h urine collections by immunoturbidimetry.

The definition of the renal status was based on the AER in at least two out of three urine collections at follow-up. Patients were classified as normoalbuminuric $(n=135)$ if their AER was persistently $<20 \mu \mathrm{g} / \mathrm{min}$ in the overnight or $<30 \mathrm{mg} / 24 \mathrm{~h}$ in the 24-h urine collection. Microalbuminuria or incipient diabetic nephropathy $(n=24)$ was defined as an AER of $20-200 \mu \mathrm{g} / \mathrm{min}$ or $30-300 \mathrm{mg} /$ $24 \mathrm{~h}$, while macroalbuminuria or established diabetic nephropathy $(n=9)$ was defined as an AER $>200 \mu \mathrm{g} / \mathrm{min}$ or $>300 \mathrm{mg} / 24 \mathrm{~h}$. Patients who were on renal replacement therapy (dialysis or kidney transplantation) were considered to have ESRD $(n=2)$. The patients with either microalbuminuria, macroalbuminuria or clinical ESRD were pooled and considered to represent diabetic nephropathy in the analyses.

Statistical analyses All analyses were performed with SPSS 12.0.1 (SPSS, Chicago, IL, USA). Baseline characteristics are presented as means $\pm \mathrm{SD}$ for normally distributed values and as median with interquartile range for non-normally distributed values, and percentages. For categorical variables the $\chi^{2}$ test or Fisher's exact test was used when appropriate. Normally distributed variables were tested with the Student's $t$ test and non-normally distributed with a Kruskal-Wallis test. Logistic regression analysis was used to adjust for age, duration of diabetes, smoking, follow-up time and BMI.

\section{Results}

Patient characteristics No clear differences were found in the baseline clinical characteristics of patients who participated in the follow-up study and those who did not (Electronic supplementary material [ESM] Table 1). Clinical characteristics are shown in Table 1. The average time period from the index pregnancy to the follow-up visit was $10.6 \pm 2.5$ years and ranged from 3.2 to 17.1 years. At the index pregnancy, women with preeclampsia were younger and more often nulliparous than patients with uncomplicated pregnancies. Patients with and without pre-eclampsia had similar BMI, whereas patients with pregnancy-induced hypertension had higher BMI than those with normal blood pressure during pregnancy.

Pre-eclampsia and diabetic complications Women with type 1 diabetes and a history of pre-eclampsia had a higher frequency of diabetic nephropathy at follow-up than women with normal blood pressure during pregnancy (41.9\% vs $8.9 \%, p<0.001)$ (Table 1$)$.

Notably, women with pre-eclampsia were more often on antihypertensive medication $(50.0 \%$ vs $9.8 \%, p<0.001)$ later in life than women with normal blood pressure during pregnancy. Patients with a history of pre-eclampsia were more likely to have CHD (12.2\% vs $2.2 \%, p=0.03)$. All three patients with a history of myocardial infarction had developed pre-eclampsia during pregnancy.

In the logistic regression analysis, both pre-eclampsia $(p<0.001)$ and $\mathrm{HbA}_{1 \mathrm{c}}$ (all three trimesters) during pregnancy $(p<0.05)$ were independently associated with diabetic nephropathy in a model that also included follow-up time, BMI, smoking, diabetes duration and age (Table 2).

Pregnancy-induced hypertension and diabetic complications Patients with pregnancy-induced hypertension and patients with normal blood pressure during pregnancy did not differ with regard to the development of diabetic nephropathy during follow-up ( 10.3 vs $8.9 \%, p=0.81)$. As expected, patients with pregnancy-induced hypertension used more antihypertensive medication $(41.9 \%$ vs $9.8 \%$, $p<0.001)$ than those with normal blood pressure during pregnancy (Table 1). 
Table 1 Descriptive data of patients by status during pregnancy and at follow-up
Unless otherwise stated, data are means $\pm \mathrm{SD}$ or median (interquartile range) ${ }^{\mathrm{a}} p<0.001$ and ${ }^{\mathrm{b}} p<0.05$ vs normotensive pregnancy

Patients with pre-pregnancy hypertension were excluded from the analysis $(n=23)$

${ }^{\mathrm{c}}$ White's class $\mathrm{F}$ excluded

${ }^{\mathrm{d}}$ Fisher's exact test used

\begin{tabular}{|c|c|c|c|}
\hline & $\begin{array}{l}\text { Normotensive } \\
\text { pregnancy }(n=105)\end{array}$ & Pre-eclampsia $(n=43)$ & $\begin{array}{l}\text { Pregnancy-induced } \\
\text { hypertension }(n=32)\end{array}$ \\
\hline \multicolumn{4}{|l|}{ Index pregnancy } \\
\hline Age (years) & $31.1 \pm 5.2$ & $28.3 \pm 4.0^{\mathrm{a}}$ & $28.6 \pm 5.2^{\mathrm{b}}$ \\
\hline BMI $\left(\mathrm{kg} / \mathrm{m}^{2}\right)$ & $22.5 \pm 2.8$ & $22.9 \pm 2.1$ & $23.8 \pm 3.2^{\mathrm{b}}$ \\
\hline Gestational age at delivery (weeks) & $37.5 \pm 1.4$ & $36.3 \pm 1.7^{\mathrm{a}}$ & $37.1 \pm 1.6$ \\
\hline Birthweight $\mathrm{z}$-score (SD) & $1.2 \pm 1.9$ & $1.3 \pm 1.9$ & $1.7 \pm 1.6$ \\
\hline Birthweight $(\mathrm{g})$ & $3,725 \pm 811$ & $3,433 \pm 852$ & $3,811 \pm 621$ \\
\hline $\mathrm{HbA}_{1 \mathrm{c}}$ pre-pregnancy (\%) & $7.5 \pm 1.1$ & $7.7 \pm 0.9$ & $7.3 \pm 0.7$ \\
\hline $\mathrm{HbA}_{1 \mathrm{c}}$ first trimester $(\%)$ & $7.5 \pm 1.3$ & $8.1 \pm 1.2$ & $7.0 \pm 1.6$ \\
\hline $\mathrm{HbA}_{1 \mathrm{c}}$ second trimester $(\%)$ & $7.0 \pm 1.1$ & $7.3 \pm 0.9$ & $7.1 \pm 1.3$ \\
\hline $\mathrm{HbA}_{1 \mathrm{c}}$ third trimester $(\%)$ & $7.2 \pm 1.2$ & $7.5 \pm 1.2$ & $7.4 \pm 1.4$ \\
\hline Nulliparity (\%) & 55.2 & $81.4^{\mathrm{b}}$ & 75.0 \\
\hline \multicolumn{4}{|l|}{ Follow-up } \\
\hline Age (years) & $41.7 \pm 6.6$ & $37.9 \pm 5.9^{\mathrm{b}}$ & $39.5 \pm 5.6$ \\
\hline BMI $\left(\mathrm{kg} / \mathrm{m}^{2}\right)$ & $24.9 \pm 4.3$ & $24.6 \pm 3.3$ & $25.8 \pm 4.2$ \\
\hline Duration of diabetes (years) & $24.1 \pm 8.6$ & $26.8 \pm 7.5$ & $24.4 \pm 9.6$ \\
\hline Systolic BP (mmHg) & $128 \pm 15$ & $133 \pm 14$ & $131 \pm 16$ \\
\hline Diastolic BP (mmHg) & $76 \pm 10$ & $80 \pm 8^{\mathrm{b}}$ & $79 \pm 8$ \\
\hline Total cholesterol (mmol/l) & $4.7 \pm 0.8$ & $4.7 \pm 0.8$ & $4.7 \pm 0.7$ \\
\hline HDL-cholesterol (mmo/l) & $2.0 \pm 4.7$ & $1.8 \pm 0.5^{\mathrm{b}}$ & $1.9 \pm 0.4$ \\
\hline LDL-cholesterol (mmol/l) & $2.4 \pm 0.6$ & $2.5 \pm 0.8$ & $2.4 \pm 0.6$ \\
\hline Triacylglycerol (mmol/l) & $0.7(0.3-1.6)$ & $0.9(0.4-3.1)^{\mathrm{b}}$ & $0.9(0.3-2.1)^{\mathrm{b}}$ \\
\hline $\mathrm{HbA}_{1 \mathrm{c}}(\%)$ & $8.6 \pm 1.5$ & $8.8 \pm 1.3$ & $8.7 \pm 1.6$ \\
\hline Serum creatinine $(\mu \mathrm{mol} / \mathrm{l})$ & $74.7 \pm 16.0$ & $93.3 \pm 55.5^{\mathrm{b}}$ & $74.5 \pm 12.0$ \\
\hline AER (mg/24 h) & $16.8(0.1-116)$ & $43.6(2-293)$ & $9.9(4.4-18.0)$ \\
\hline Smokers $(\%)$ & 21.7 & 15.4 & 32.3 \\
\hline Antihypertensive treatment (\%) & 9.8 & $50.0^{\mathrm{a}}$ & $41.9^{\mathrm{a}}$ \\
\hline Diabetic nephropathy $(\%)^{\mathrm{c}}$ & 8.9 & $41.9^{\mathrm{a}}$ & 10.3 \\
\hline CHD (\%) & 2.2 & $12.2^{\mathrm{bd}}$ & 3.2 \\
\hline Myocardial infarction (\%) & 0 & $7.3^{\text {bd }}$ & 3.2 \\
\hline
\end{tabular}

Pregnancy characteristics and outcome Poor glycaemic control during pregnancy (irrespective of the trimesters) predicted diabetic nephropathy $(p<0.001)$ later in life (Table 3).

A large difference between $\mathrm{HbA}_{1 \mathrm{c}}$ at pregnancy (the third trimester) and follow-up was associated with increased risk of diabetic nephropathy, supporting the role of glucose exposure as a risk factor for diabetic nephropathy (data not shown).

\section{Discussion}

The most important finding of this study was that women with type 1 diabetes and pre-eclampsia during pregnancy were much more likely to develop diabetic nephropathy and high blood pressure later in life than women with type 1 diabetes and normal blood pressure during pregnancy. Interestingly, pregnancy-induced hypertension in women with type 1 diabetes was not associated with diabetic nephropathy later in life, which suggests that pre-eclampsia

Table 2 Logistic regression analysis for diabetic nephropathy

\begin{tabular}{|c|c|c|c|c|c|c|}
\hline & OR & $95 \% \mathrm{CI}$ & $p$ value & Adjusted OR & $95 \% \mathrm{CI}$ & $p$ value \\
\hline Pre-eclampsia & 7.4 & $2.7-20.5$ & $<0.001$ & $7.7^{\mathrm{a}}$ & $1.6-36.1^{\mathrm{a}}$ & $0.01^{\mathrm{a}}$ \\
\hline $\mathrm{HbA}_{1 \mathrm{c}}$ first trimester & 3.2 & $1.5-6.9$ & 0.003 & $3.2^{\mathrm{b}}$ & $1.3-7.9^{\mathrm{b}}$ & $0.01^{\mathrm{b}}$ \\
\hline $\mathrm{HbA}_{1 \mathrm{c}}$ second trimester & 3.7 & $1.8-7.9$ & $<0.001$ & $4.0^{\mathrm{b}}$ & $1.7-9.8^{\mathrm{b}}$ & $0.002^{\mathrm{b}}$ \\
\hline $\mathrm{HbA}_{1 \mathrm{c}}$ third trimester & 2.1 & $1.2-3.6$ & 0.01 & $2.0^{\mathrm{b}}$ & $1.1-3.8^{\mathrm{b}}$ & $0.03^{\mathrm{b}}$ \\
\hline
\end{tabular}

${ }^{a}$ Adjusted for BMI, follow-up time, smoking, duration of diabetes, age and the average of the $\mathrm{HbA}_{1 \mathrm{c}}$ measurements during all three trimesters

${ }^{\mathrm{b}}$ Adjusted for BMI, follow-up time, smoking, duration of diabetes and age

$O R$, odds ratio 
Table 3 Clinical characteristics of the patients at index pregnancy by kidney status at follow-up

\begin{tabular}{lll}
\hline & $\begin{array}{l}\text { Normal } \\
\text { AER } \\
(n=135)\end{array}$ & $\begin{array}{l}\text { Diabetic } \\
\text { nephropathy } \\
(n=35)\end{array}$ \\
\hline Index pregnancy & & \\
Age (years) & $30.1 \pm 5.0$ & $30.0 \pm 5.1$ \\
BMI (kg/m $\left.{ }^{2}\right)$ & $22.8 \pm 3.0$ & $23.4 \pm 2.9$ \\
Gestational age at delivery (weeks) & $37.3 \pm 1.5$ & $35.6 \pm 2.1^{\mathrm{a}}$ \\
Birthweight z-score (SD) & $1.6 \pm 1.7$ & $1.0 \pm 1.9$ \\
$\mathrm{Birthweight} \mathrm{of} \mathrm{fetus} \mathrm{(g)}_{\text {HbA }}$ pre-pregnancy (\%) & $3,812 \pm 718$ & $3,200 \pm 902^{\mathrm{a}}$ \\
$\mathrm{HbA}_{1 \mathrm{c}}$ first trimester (\%) & $7.3 \pm 1.0$ & $7.8 \pm 0.8$ \\
$\mathrm{HbA}_{1 \mathrm{c}}$ second trimester (\%) & $7.4 \pm 1.3$ & $8.8 \pm 0.9^{\mathrm{a}}$ \\
$\mathrm{HbA}_{1 \mathrm{c}}$ third trimester (\%) & $6.9 \pm 1.9$ & $8.1 \pm 1.1^{\mathrm{a}}$ \\
$\mathrm{Pre}^{\mathrm{a}}$ eclampsia (\%) & $7.1 \pm 1.1$ & $8.0 \pm 1.3^{\mathrm{b}}$ \\
Pregnancy-induced hypertension (\%) $^{\mathrm{b}}$ & 24.1 & $61.9^{\mathrm{a}}$ \\
Non-hypertensive pregnancy (\%) & 57.9 & 27.3 \\
\hline
\end{tabular}

Data are means $\pm \mathrm{SD}$

${ }^{\mathrm{a}} p<0.001$ and ${ }^{\mathrm{b}} p<0.05$ vs normal AER

Patients with White's class F (or pre-pregnancy hypertension) and patients that could not be appropriately classified for kidney status were excluded from the analysis $(n=33)$

and pregnancy-induced hypertension are two different diseases. This was also suggested by Hiilesmaa et al. [6], who found that pre-eclampsia but not pregnancy-induced hypertension was associated with glycaemic control during the first half of pregnancy. Notably, poor glycaemic control during pregnancy was a risk factor for subsequent diabetic nephropathy in this study.

Earlier studies indicate that in the general population pre-eclampsia predisposes women to macrovascular complications $[12,13]$. This seems to be the case in patients with type 1 diabetes as well, since we found that women with type 1 diabetes and a history of pre-eclampsia had more CHD at follow-up than type 1 diabetic women with normal blood pressure during pregnancy. They also had lower HDL-cholesterol, higher triacylglycerol and elevated diastolic blood pressure.

As far as we know, the only study that shows pre-eclampsia to be a risk factor for diabetic microvascular disease is that by Lowestam-Adrian et al. [16], which suggests an association with retinopathy. The present study indicates that type 1 diabetic women with previous pre-eclampsia have an increased risk of developing diabetic nephropathy.

The diagnosis of diabetic nephropathy deserves some clarification. We pooled all patients with microalbuminuria, macroalbuminuria and ESRD and classified them as representing diabetic nephropathy. Thus although microalbuminuria is a strong predictor of clinical nephropathy in patients with type 1 diabetes [19, 28], further follow-up of our cohort will reveal the true impact of pre-eclampsia on the development of overt proteinuria, and eventually ESRD.

A limitation of the study is that microalbuminuria was not quantitatively measured before and during pregnancy. However, a dipstick test was used at each antenatal visit every 2-4 weeks from weeks $6-10$ of pregnancy and onwards. Thus, albuminuria greater than approximately $0.3 \mathrm{~g}$ during early pregnancy can be excluded. A definite diagnosis of pre-eclampsia in type 1 diabetic patients with proteinuria during the first half of pregnancy is difficult to make. Therefore, these patients were excluded in the analyses for nephropathy.

The relation between pre-eclampsia and poor glycaemic control is an important, albeit rarely studied issue. Our own experience supports the study by Rudge et al. [29], namely that although poor glycaemic control is associated with pre-eclampsia [6], it does not seem to trigger onset of pre-eclampsia. We cannot, however, rule out the possibility that patients with pre-eclampsia may also have poor glycaemic control after their pregnancy, which would also increase their risk of diabetic nephropathy. Unfortunately, as long as we lack clinical data (e.g. blood pressure, $\mathrm{BMI}, \mathrm{HbA}_{1 \mathrm{c}}$, smoking) from the time period between pregnancy and follow-up visit, this hypothesis cannot be tested. In any case, the $\mathrm{HbA}_{1 \mathrm{c}}$ values measured either prior to pregnancy or at follow-up did not differ between pre-eclamptic patients and those with normotensive pregnancies. In addition, $\mathrm{HbA}_{1 \mathrm{c}}$ was included in the logistic regression analyses for diabetic nephropathy (Table 2) and showed that pre-eclampsia was an independent risk factor for diabetic nephropathy with an odds ratio of 7.7 .

An important question that arises is whether non-diabetic women with pre-eclampsia also have a higher risk of kidney disease. In this study we did not have such a group. However, in an earlier study we followed pre-eclamptic women for 5 years and studied their renal and vascular function. None of these women had signs of kidney disease, although they had had massive proteinuria during pregnancy [30].

The mechanisms leading to renal disease in type 1 diabetic patients are not fully understood. One theory is that it has to do with dysfunction of the endothelial lining of the arteries, a phenomenon that has been shown in both preeclampsia and diabetic nephropathy [22, 31]. Moreover, an inflammatory process has been observed in both entities $[32,33]$. Pre-eclampsia sometimes involves massive proteinuria, which resolves after delivery, but the endothelial dysfunction may remain [11]. However, at the morphological level pre-eclampsia seems to be quite different from diabetic nephropathy. In pre-eclampsia, the glomerular changes are characterised by endothelial swelling and oedema of the glomerular basement membrane, while the glomerulosclerotic lesions tend to be focal, with resem- 
blance of lesions seen in different forms of glomerulonephritis $[34,35]$. Diabetic nephropathy, on the other hand, is characterised by thickening of the basement membrane and increase in the mesangial matrix. This results in diffuse glomerulosclerosis [36]. It could be speculated that preeclampsia causes an insult to the kidney, which predisposes to nephron loss and further to diabetic nephropathy in susceptible individuals.

It can also be speculated that there is a common genetic background for pre-eclampsia [37, 38] and diabetic nephropathy, possibly through endothelial dysfunction, chronic inflammation and insulin resistance. Those diabetic women who develop pre-eclampsia might have a greater risk of developing endothelial dysfunction before pregnancy. No direct measurements of endothelial dysfunction prior to pre-eclamptic pregnancy was performed. However, according to the Steno hypothesis, microalbuminuria could be considered a marker of generalised vascular dysfunction [39]. Since microalbuminuria is a risk factor for preeclampsia, this gives indirect evidence for a possible role of endothelial dysfunction [9]. Another possibility is that pregnancy itself, as a state of hypervolaemia, acquired thrombophilia, insulin resistance and low-grade inflammation, could induce pre-eclampsia as the first manifestation of endothelial dysfunction [40]. In any case, pregnancy itself worsens kidney function shortly after delivery, even in persons without kidney disease, but this does not persist in the long term [41-43].

Taken together, our results indicate that type 1 diabetic women with pre-eclampsia require more intensive followup after their pregnancies with special emphasis on early detection of microalbuminuria. Once detected, interventions aiming at normoglycaemia, normal blood pressure and a reduced AER should be considered in order to prevent development of diabetic nephropathy.

In conclusion, these data suggest that a history of preeclamptic pregnancy but not pregnancy-induced hypertension is associated with an elevated risk of diabetic nephropathy. This suggests that an early start to renoprotective medication in type 1 diabetic women with prior preeclampsia could be beneficial.

Acknowledgements The study was supported by grants from the Folkhälsan Research Foundation, the Wilhelm and Else Stockmann Foundation, the Sigrid Juselius Foundation, the Liv och Hälsa Foundation, the Finnish Medical Society (Finska Läkaresällskapet), the Perklén Foundation, and the European Commission (QLG2-CT2001-01669). The skilled technical assistance of the FinnDiane Study Group is gratefully acknowledged. See the Electronic supplementary material for a list of participating centres.

Duality of interest The authors have stated that they have no financial disclosures or conflicts of interest to declare.

\section{References}

1. Redman CW, Sargent IL (2005) Latest advances in understanding preeclampsia. Science 308:1592-1594

2. Roberts JM, Cooper DW (2001) Pathogenesis and genetics of pre-eclampsia. Lancet 357:53-56

3. Chambers J, Fusi L, Malik I, Haskard D, De Swiet M, Kooner J (2001) Association of maternal endothelial dysfunction with preeclampsia. JAMA 285:1607-1612

4. Walker JJ (2000) Pre-eclampsia. Lancet 356:1260-1265

5. Ewers IM, de Valk HW, Visser GHA (2004) Risk of complications of pregnancy in women with type 1 diabetes: nationwide prospective study in the Netherlands. $\mathrm{Br}$ Med $\mathrm{J}$ 328:915-921

6. Hiilesmaa V, Suhonen L, Teramo K (2000) Glycaemic control is associated with pre-eclampsia but not with pregnancy-induced hypertension in women with type I diabetes mellitus. Diabetologia 43:1534-1539

7. Combs CA, Rosenn B, Kitzmiller JL, Khoury JC, Wheeler BC, Miodovnik M (1993) Early-pregnancy proteinuria in diabetes related to preeclampsia. Obstet Gynecol 82:802-807

8. Sibai BM, Caritis S, Hauth J et al (2000) Risks of preeclampsia and adverse neonatal outcomes among women with pregestational diabetes mellitus. National institute of child health and human development network of maternal-fetal medicine units. Am J Obstet Gynecol 182:364-369

9. Ekbom P, Damm P, Feldt-Rasmussen B, Feldt-Rasmussen U, Molvig J, Mathiesen ER (2001) Pregnancy outcome in type 1 diabetic women with microalbuminuria. Diabetes Care 24:17391744

10. Hanson U, Persson B (1998) Epidemiology of pregnancy-induced hypertension and preeclampsia in type 1 (insulin-dependent) diabetic pregnancies in Sweden. Acta Obstet Gynecol Scand 77:620-624

11. Lampinen KH, Rönnback M, Kaaja RJ, Groop PH (2006) Impaired vascular dilatation in women with a history of preeclampsia. J Hypertens 24:751-756

12. Irgens HU, Reisaeter L, Irgens LM, Lie RT (2001) Long term mortality of mothers and fathers after pre-eclampsia: population based cohort study. Br Med J 7323:1213-1217

13. Hannaford P, Ferry S, Hirsch S (1997) Cardiovascular sequelae of toxaemia of pregnancy. Heart 2:154-158

14. Haukkamaa L, Salminen M, Laivuori H, Leinonen H, Hiilesmaa V, Kaaja R (2004) Risk for subsequent coronary artery disease after preeclampsia. Am J Cardiol 6:805-808

15. Kaaja R, Sjöberg L, Hellsted T, Immonen I, Sane T, Teramo K (1996) Long-term effects of pregnancy on diabetic complications. Diabet Med 13:165-169

16. Lovestam-Adrian M, Agardh CD, Aberg A, Agardh E (1997) Preeclampsia is a potent risk factor for deterioration of retinopathy during pregnancy in type 1 diabetic patients. Diabet Med 14:1059-1065

17. Miodovnik M, Rosenn BM, Khoury JC, Grigsby JL, Siddiqi TA (1996) Does pregnancy increase the risk for development and progression of diabetic nephropathy? Am J Obstet Gynecol 174:1180-1189

18. Mogensen CE, Christensen CK (1984) Predicting diabetic nephropathy in insulin-dependent patients. $\mathrm{N}$ Engl J Med 311:89-93

19. Viberti GC, Hill RD, Jarrett RJ, Argyropoulos A, Mahmud U, Keen $\mathrm{H}$ (1982) Microalbuminuria as a predictor of clinical nephropathy in insulin-dependent diabetes mellitus. Lancet 1:1430-1432

20. Krolewski AS, Warram JH, Christlieb AR, Busick EJ, Kahn CR (1985) The changing natural history of nephropathy in type 1 diabetes. Am J Med 78:785-794 
21. Andersen AR, Christiansen JS, Andersen JK, Kreiner S, Deckert T (1983) Diabetic nephropathy in type 1 (insulin-dependent) diabetes: an epidemiological study. Diabetologia 25:496-501

22. Stehouwer C, Gall M, Twisk J, Knudsen E, Emeis J (1997) Endothelial dysfunction and the pathogenesis of diabetic angiopathy. Cardiovasc Res 34:55-68

23. Rossing P, Hougaard P, Parving H-H (2002) Risk factors for development of incipient and overt diabetic nephropathy in type 1 diabetic patients: a 10-year prospective observational study. Diabetes Care 25:859-864

24. Scott LJ, Warram JH, Hanna LS, Laffel LM, Ryan L, Krolewski AS (2001) A nonlinear effect of hyperglycemia and current cigarette smoking are major determinants of the onset of microalbuminuria in type 1 diabetes. Diabetes 50:2842-2849

25. Caritis S, Sibai B, Hauth J et al (1998) Predictors of pre-eclampsia in women at high risk. National institute of child health and human development network of maternal-fetal medicine units. Am J Obst Gynecol 4:946-951

26. Levine RJ, Ewell MG, Hauth JC et al (2000) Should the definition of preeclampsia include a rise in diastolic blood pressure of $\geq 15 \mathrm{~mm} \mathrm{Hg}$ to a level $<90 \mathrm{~mm} \mathrm{Hg}$ in association with proteinuria? Am J Obst Gynecol 183:787-792

27. National High Blood Pressure Education Program Working Group on High Blood Pressure in Pregnancy (2000) Report of the national high blood pressure education program working group on high blood pressure in pregnancy. Am J Obst Gynecol 183:S1-S22

28. Forsblom CM, Groop P-H, Ekstrand A, Groop L (1992) Predictive value of microalbuminuria in patients with insulindependent diabetes of long duration. Br Med J 305:1051- 1053

29. Rudge MV, Calderon IM, Ramos MD, Peracoli JC, Pim A (1997) Hypertensive disorders in pregnant women with diabetes mellitus. Gynecol Obstet Invest 44:11-15

30. Lampinen K, Rönnback M, Groop P-H, Kaaja R (2006) Renal and vascular function in women with previous preeclampsia: a comparison of low- and high-degree proteinuria. Kidney Int 70:1818-1822

31. Roberts JM, Taylor RN, Musci TJ, Rodgers GM, Hubel CA, McLaughlin MK (1989) Preeclampsia: an endothelial cell disorder. Am J Obst Gynecol 161:1200-1204
32. Luppi P, Deloia JP (2006) Monocytes of preeclamptic women spontaneously synthesize pro-inflammatory cytokines. Clin Immunol 118:268-275

33. Saraheimo M, Forsblom C, Hansen TK et al; FinnDiane Study Group (2005) Increased levels of mannan-binding lectin in type 1 diabetic patients with incipient and overt nephropathy. Diabetologia 48:198-202

34. Spargo BH, McCartney CP, Winemiller R (1959) Glomerular capillary endotheliosis in toxemia of pregnancy. Arch Pathol 68:593-599

35. Gärtner HV, Sammoun A, Wehrmann M, Grossmann T, Junghans R, Weihing C (1998) Preeclamptic nephropathy - an endothelial lesion. A morphological study with a review of the literature. Eur J Obstet Gynaecol 77:11-27

36. Österby R (1992) Glomerular structural changes in type 1 (insulin-dependent) diabetes mellitus: causes, consequences, and prevention. Diabetologia 35:803-812

37. Arngrimsson R, Bjornsson S, Gersson RT, Bjornsson II, Walker JJ, Snaedal G (1990) Genetic and familial predisposition to eclampsia and preeclampsia in a defined population. Br J Obstet Gynaecol 97:131-140

38. Cooper DW, Brennecke SP, Wilton AN (1993) Genetics of preclampsia. Hypertens Pregnancy 12:1-23

39. Deckert T, Feldt-Rasmussen K, Borch-Johnsen K, Jensen T, Kofoed-Enevoldsen A (1989) Albuminuria reflects widespread vascular damage. The Steno hypothesis. Diabetologia 32:219226

40. Kaaja RJ, Greer IA (2005) Manifestations of chronic disease during pregnancy. JAMA 294:2751-2757

41. Kaaja R, Sjöberg L, Hellstedt T, Immonen I, Sane T, Teramo K (1996) Long-term effects of pregnancy on diabetic complications. Diabet Med 13:165-169

42. Chaturvedi N, Stephenson JM, Fuller JH (1995) The relationship between pregnancy and long-term maternal complications in the EURODIAB IDDM Complications Study. Diabet Med 12:494-499

43. Purdy LP, Hantsch CE, Molitch ME et al (1996) Effect of pregnancy on renal function in patients with moderate-to-severe diabetic renal insufficiency. Diabetes Care 19:1067-1076 